\title{
An exploration of sustainability between productivity and ecological stability in montane planted and natural forests in Sichuan, China
}

\author{
Ting $\mathrm{Li}^{1}$, Qi Wang ${ }^{2}$, Yang Liu ${ }^{3}$, Changhong Lai ${ }^{3}$, Heng $\mathrm{Lu}^{1}$, Yuming Qiu ${ }^{4}$, and Li Peng ${ }^{5}$ \\ ${ }^{1}$ Sichuan Normal University \\ ${ }^{2}$ Chinese Academy of Fishery Sciences \\ ${ }^{3}$ Sichuan Forestry and Grassland Research and Planning Institute \\ ${ }^{4}$ Chinese Academy of Sciences \\ ${ }^{5}$ Institute of Mountain Hazards and Environment, CAS
}

February 22, 2022

\begin{abstract}
Implementation of the Natural Forest Protection Project and Grain for Green Programme in China has promoted forest restoration, increased productivity, and enhanced the carbon stocks. However, few studies have characterized temporal and spatial variation in productivity and ecological stability in planted and natural forests and evaluated the factors driving such variation. In this study, we used 1399 permanent forest plots to identify change patters in the productivity and temporal stability of above-ground biomass (AGB) and evaluated the factors driving these changes in planted and natural forests in Sichuan Province, China. The mean temporal stability of AGB was higher for natural forest than for planted forest from 1979 to 2017; While, the productivity of planted forest was higher. The stability decreased at a rate of -0.013 yr-1 in entire natural forest and $-0.011 \mathrm{yr}-1$ in planted forests, and the productivity of natural forest decreased significantly over time, with a slope of $-0.0065 \mathrm{Mg}$ ha-1 yr-1 per calendar year. Altitude, latitude, annual precipitation, and stand age dominated variability in the productivity and AGB stability of natural forest. Richness, tree density, and stand age were the determinants of productivity and stability in planted forest. Our results suggest that selective thinning and enriching species richness and forest stand age can effectively balance the productivity and biomass temporal stability of planted forests. Older natural forests still need to be strictly protected under climate change.
\end{abstract}

\section{Introduction}

Over the last several decades, China has been carrying out two ecological restoration programs: the Natural Forest Protection Project (NFP) and the Grain for Green Programme (GGP). These two projects have increased the area of forest (Zhang et al., 2020), restored degraded environments (Ren et al., 2017), and enhanced carbon stocks in natural and planted forests (Pawson et al., 2013). Furthermore, the Chinese government has implemented stricter protection measures, which included the prohibition of commercial logging in natural forests, especially in ecological sensitive areas. The competition between different uses of land such as agricultural production, timber production, and ecological services has increased. Optimizing the sustainability of the supply of competing services from forests requires consideration of potential trade-offs between them. The goal of planted forest restoration in China has been shifted from increasing productivity and coverage to developing the ecological function of approximate natural forest with diversity species, high water and soil conservation function, natural succession and sustainable carbon sequestration function. This goal is consistent with the target of "close-to-nature-management" (Wang et al., 2018), which will not only develop mixed and uneven-aged, structurally diverse forests, restore forest productivity but will also focus on 
the stand stability and reliance of forest ecosystems. The design of plantations that complement the services provided by natural forest is particularly important in the face of future environment change, as plantations are often monocultures with alien species (Verheyen et al., 2016). Generally, the quality of plantations needs to be improved while balancing productivity and other ecological services.

The definition of biomass temporal stability is the ratio of mean value to the standard deviation of biomass across time, which is an important indicator of ecological stability (Hautier et al., 2015; Morin et al., 2014). The insurance hypothesis, which postulates that biodiversity improves ecosystem stability, has been widely studied (García-Palacios et al., 2018). To improve the quality of planted forest, we need to know what are relationship among biodiversity, productivity and ecosystem stability (Domínguez-García et al., 2019). Because planted forests are thought to have lower diversity, productivity, and ecological stability compared with natural forests during the long-term recovery process (Ke et al., 2020; Zhang et al., 2020). Previous experiments have shown that more tree species can increase productivity and provide more ecosystem services than monoculture (Aussenac et al., 2019). However, whether such an effect applies to natural ecosystems remains unclear. Some studies have found a positive concave relationship between biodiversity and productivity change within a sampling unit and spatial scale in a global data set (Liang et al., 2016; Luo et al., 2019). Forest biomass increased over time in forest with high tree diversity, while which decreased with time in poor species forest in Canada (Hisano et al., 2019). In Europe, the stability of biomass was more stability in mixed forests (Jucker et al., 2014). While, one to two stability indicators at a time and response to a single disturbance were usually quantified in the existing studies (Domínguez-García et al., 2019).

In natural ecosystems, the effects of environmental context (Ratcliffe et al., 2017; Mori et al., 2018), climate change (García-Palacios et al., 2018), stand structure (Guo et al., 2021; Ouyang et al., 2019) and diversity have effect on forest productivity and ecosystem stability, the effects also may vary in time and space. Furthermore, these factors interact and become more complex. It's difficult to weigh these effects against each other in natural ecosystems. (Isbell et al., 2017; Isbell et al., 2019). While, Hautier et al. (2015) think the ecosystem stability is mainly altered by factors that affect biodiversity in the global drought gradient. For example, climate change may transform the certain relationship between biodiversity and ecosystem stability (García-Palacios et al., 2018). Therefore, Yao et al. (2018) thought that mean annual temperature was the main effect factor for forest productivity change. While, Ouyang et al. (2019) suggested that forest structure, for example stand age and density manipulated forest productivity in subtropical in China. Elevation and soil fertility only had significant effects on biomass in forests less than 100 years old, and which were mainly affected by biological interaction in older forest (Satdichanh et al., 2019). The change rate of biomass would decrease with stand age (Chen and Luo, 2015). The NFP and the GGP have been in operation for nearly 20 years. Most forest plantations are young and were only established between 1999 and 2014 on sloped terrain. Most studies have focused on the productive and ecological benefits of increased forest cover (Brown et al., 2020; Cook-Patton et al., 2020; Deng et al., 2017; Tong et al., 2020). Temporal and spatial variation in productivity and ecological stability between planted and natural forests have received less attention by comparison. In addition, how environmental context, climate change and forest structure factors affect forest productivity and ecological stability in a spatially heterogeneous mountain ecosystem remains unclear, and this knowledge gap increases the difficulty of restoring and reconstructing planted forests in mountain ecosystems.

Here, we studied spatio-temporal productivity and ecological stability patterns, identified the main factors that explained changes in the productivity and ecological stability of planted and natural forests, and explored the coupling effects between the most important factors. It is relevant and timely to boost sustainable forest management policies according to environmental conditions and forest structures, especially in planted forest. Generally, this study provides a new insight that will aid the improvement of quality, functionality and productivity planted forest, and help balance productivity and ecological stability in the future.

\section{Materials and Methods}

\subsection{Study area}


Our study area is located on the southwest mountain of Sichuan Province (Fig. 1), which experienced heavy deforestation starting in the 1950s and is the site of implementation of NFP and GGP. The forest area has recovered rapidly. By 2019, the forest coverage rate has reached $40 \%$ in Sichuan province (Cui H., and Liu M., 2020), exceeding the world average (30\%). The forest types contain subtropical evergreen broad-leaved forest, deciduous broad-leaved forest, coniferous broad-leaved mixed forest and cold temperate coniferous forest (Sichuan Vegetation Cooperation Group, 1980). The climate is sub-humid subtropical climate. The study area represents the 'ecological protective screen' for the upstream Yangtze River catchment that has a great national significance for water, soil and biodiversity conservation.

\subsection{Forest inventory data}

We used a survey database of permanent sampling plotsin natural and planted forests across Sichuan Province, China. The database was based on systematic inventory records of trees, including latitude, longitude, altitude, slope, aspect, soil depth, soil type, human disturbance, tree species, diameter at breast height $(\mathrm{DBH})$, tree height, mean stand age, tree density (individual/ha), stand volume $\left(\mathrm{m}^{3}\right)$, canopy $(\%)$, and disaster (fires, insect infestations). Forest inventory data were obtained for eight years $(1979,1988,1992,1997$, $2002,2007,2012$, and 2017). The sample plots were set according to the kilometer grid $2^{\mathrm{n}}(\mathrm{km})(\mathrm{n}=2,3)$. Each stem with DBH $(1.3 \mathrm{~m})$ [?] $5 \mathrm{~cm}$ was recorded, and trees of height $<1.5 \mathrm{~m}$ were classified as understory trees. Trees that only reached the DBH threshold after a first (set of) census(es) were classified as recruits.

Permanent sampling plots were set to assess the dynamics of forests of varying ages in the study area by the provincial government of Sichuan. These plots areas were 0.067 ha $(25.84 \mathrm{mx} 25.84 \mathrm{~m})$. There was no massive pest infestation in our study area. We chose permanent plots on the basis of the four criteria for characterizing long-term changes in forests: 1) origin is known, and obvious interfering events have not taken place (replanting, logging, fire, river flood discharges, storm severity); 2) at least more than two censuses have been performed; 3) lack of obvious wrong data and missing data, and 4) mean stand age estimation is available since it was first recorded.

A total of 1,399 permanent plots (ca. 135 ha, 1,248 natural forest plots, 151 planted forest plots) met our inclusion criteria. The latitude of 1,399 plots is from $26 @ 12^{\prime} \mathrm{N}$ to $34 @ 14$ ' $\mathrm{N}$, the longitude of the plots is from 98@39'E to 104@24'E (Fig. 1) and the altitude is from $400 \mathrm{~m}$ to $4460 \mathrm{~m}$ above sea level. In the selected plots, 136,988 live trees were measured from 1979 to 2017. The mean measurement interval in natural forests was $6.07 \pm 2.08$, whereas that of planted forest was $5.75 \pm 2.05$. The dominant genera across all censuses and plots wereAbies sp. , Picea sp. , Betula sp. ,Tsuga sp. , Sabina sp., Pinus sp., Eucalyptus sp., Populus sp., Tilia sp., and Acer sp. The basic information of permanent plots in natural and planted forest are shown in Table S1.

\subsection{Climatic, forest structure, and environmental context data}

The data set was divided into meteorological data, forest structure data, and environmental context data. The meteorological data included annual precipitation and mean annual temperature (MAT). Forest structure data included tree density (individual/ha), canopy (\%), DBH $(\mathrm{cm})$, mean stand age, and tree height $(\mathrm{m})$. Environmental context data included soil depth $(\mathrm{cm})$, soil type, slope (degree), aspect (degree), altitude (m), and latitude (degree).

\subsubsection{Climate data}

Monthly and annual climatic data (annual precipitation and MAT) were collected from 1979 to 2017 at 65 weather stations located within our study region. We used Kriging interpolation method to interpolate meteorological data with a spatial resolution of $1 \mathrm{~km} \times 1 \mathrm{~km}$ and regionalize the various variables at different scales. Further interpolations were conducted to adjust the temperature to the respective mean plot elevation (Piao et al., 2011). We used this approach to calculate the mean value of the MAT and annual precipitation from 1979 to 2017 for each plot. And then, we used linear regression model to analysis the MAT and annual precipitation change over time (see Fig S2).

\subsubsection{Temporal stability of AGB and productivity}


We calculated productivity $\left(\mathrm{Mg} \mathrm{ha}^{-1} \mathrm{year}^{-1}\right)$ and AGB temporal stability per period for each plot. Productivity represents the change in AGB over time.

Temporal stability $=\mu / \mathrm{SD}$,

$\mu$ : Mean AGB from the initial time to the final survey time for each plot.

SD: standard deviation of AGB from the initial time to the final survey time for each plot.

Plot-level AGB ( $\mathrm{Tg} \mathrm{ha}^{-1}$ ) was calculated by summing up the biomass of all live trees $>5 \mathrm{~cm}$ in $\mathrm{DBH}$ in each plot at each measurement. AGB of each live tree was assessed using the "scaling-up factor continuous function" method (Fang et al., 2001) and did not include litterfall production. This method is considered accurate for estimating forest biomass at regional scales.

\subsection{Statistical analysis}

Firstly, we inspected bivariate relationships between forest productivity/AGB stability and the individual predictor factors (Fig. S1). We used $t$-tests to analyze whether the mean temporal stability of AGB or productivity differed between planted forests and natural forests. Secondly, a linear mixed effect model (LME) was used to analyze the trend in AGB stability and productivity over time in planted forest and natural forest, "year" as a fixed effect and "plot" as a random effect. We also analyzed whether there were differences in stability and productivity in the two forest types over time. The mean stability and productivity were z-transformed prior to all analyses.

2.4.1 Identify the main influencing factors for AGB temporal stability and productivity in planted and natural forests

We used generalized least squares models (GLS) and LME to assess the joint effects of climatic, forest structure, and environmental factors on stability and productivity. Based on the AIC (Akaike's information criterion) for GLS and LME models (Zuur et al., 2009), we fit the joint effects using GLS models with a Gaussian error structure with the "nlme" (v3.1-150) software package (Pinheiro, 2020). All environmental and forest structure variables and climatic variables were z-transformed to facilitate interpretation of parameter estimates. We also tested for multi-collinearity; predictors with sufficiently low variance inflation factors $(\mathrm{VIF}<5)$ were included in the model.

We carried out a model-averaging procedure on the basis of AIC $(\Delta \mathrm{AIC}<4)$ to decide parameter standard coefficients (Grueber et al., 2011) for the main influencing factors of stability and productivity for planted and natural forests using a dredge function in the "MuMIn" package (Barton, 2015). We considered spatial autocorrelation (SCV) based on latitude and longitude in the GLS model (Rousset et al. 2018). All response and prediction variables were calculated as averages in the continuous investigation cohort. The structure of our GLS model is as follows:

Stability/Productivity $\sim \vartheta_{\operatorname{clim}}+\vartheta_{\text {fore }}+\vartheta_{\text {envi }}+\mathrm{SCV}+e$,

where $\vartheta_{\text {clim }}$ are the climatic variables (annual precipitation, MAT), $\vartheta_{\text {fore }}$ are the mean values of variables describing forest structure (canopy cover, stand age, abundance, richness, DBH, tree height, and tree density), and $\vartheta_{\text {envi }}$ are environmental context variables (latitude, altitude, aspect, slope, and soil depth); SCV refers to the spatial correlation variance structure. $e$ represents the residual. All terms were modeled as additive effects, and no interactions were calculated in this top model.

Considering potential nonlinear responses of AGB stability and productivity to different factors, we used the "mgcv" R-package to fit the effect of forest structure in generalized additive mixed models (GAMM) (Fig. S3) (Wood, 2017). The effects of different factors in the GAMM and GLS were then compared.

2.4.2 Compare the coupling relationships between climate, forest structure, environmental factors, stability, and productivity in natural and planted forests 
We used "piecewiseSEM" package (Lefcheck, 2016) to match Structural equation modeling (SEM) to uncover the effects of all explaining variables on forest stability and productivity in planted and natural forests. We concentrated the SEM analysis on diversity-productivity, forest structure-productivity, and climaticstability relationships. To inspect whether forest structure factors, climatic factors, and environmental factors simultaneously affect trees species diversity, we also fitted paths between structural factors, climatic and environmental factors, and diversity. Standardized path coefficients were used to measure the coupling effects of predictors. All analyses were performed in R v4.0.2 (R Core Team, 2018).

\section{Results}

\subsection{Stability and productivity in planted and natural forest}

Natural forests showed greater temporal stability in AGB than planted forests over the last four decades ( $\mathrm{T}$ value $=5.19, \mathrm{P}<0.0001$ ) (Fig. 2a). Despite the low diversity of planted forest (often with a single tree species), the AGB stocks of planted forest $\left(0.028 \pm 0.027 \mathrm{Tg} \mathrm{ha}^{-1}\right)$ was similar to that of natural forest $(0.029 \pm 0.028$ $\mathrm{Tg} \mathrm{ha} \mathrm{g}^{-1}$ ); however, the productivity of planted forest was much higher compared with natural forest ( $\mathrm{T}$ value $=4.65, \mathrm{P}<0.001)$ (Fig. 2b). AGB stability significantly decreased at a rate of $-0.013 \mathrm{yr}^{-1}(\mathrm{~T}$ value $=-$ 9.06, $\mathrm{df}=4893, \mathrm{P}<0.0001)$ in natural forest and $-0.011 \mathrm{yr}^{-1}(\mathrm{~T}$ value $=-3.53, \mathrm{df}=546, \mathrm{P}<0.0001)$ in planted forests (Fig. 3a). There was a significant decrease in productivity $(\mathrm{T}$ value $=-4.76, \mathrm{df}=4893, \mathrm{P}<0.0001)$ in natural forest, with a slope of $-0.0065 \mathrm{Mg} \mathrm{ha}^{-1}$ year $^{-1}$ per calendar year; productivity in planted forest did not change significantly (Fig. 3b).

\subsection{Environmental and forest structure predictors of productivity and AGB stability in planted and natural forests}

In natural forest, annual precipitation ( $\mathrm{Z}$ value $=3.47, \mathrm{P}=0.00053$ ) and latitude $(\mathrm{Z}$ value $=2.04, \mathrm{P}=0.042$ ) had a negative effect on AGB stability in the conditional average models after accounting for spatial autocorrelation (Fig. 4a). AGB stability was higher in natural forest plots with older stand age and higher altitude (Fig. 4a). However, richness $(\mathrm{Z}$ value $=1.95, \mathrm{P}=0.055)$ and stand age $(\mathrm{Z}$ value $=1.71, \mathrm{P}=0.087)$ were not significantly related to AGB stability in planted forest in the conditional average models (Fig. 4a). Based on the GAMM model, there was a significant non-linear relationship of tree density ( $\mathrm{F}$ value $=6.12, \mathrm{P}<0.0001$ ) and stand age $(\mathrm{F}$ value $=8.64, \mathrm{P}<0.0001)$ with stability in natural forest (Fig. S3 a and c). And, there was no significant association between richness and stability in natural forest ( $\mathrm{F}$ value $=0.97, \mathrm{P}=0.34$ ) and planted forest $(\mathrm{F}$ value $=3.81, \mathrm{P}=0.053$ ) (Fig. S3b) in GAMM model. In addition, density ( $\mathrm{F}$ value $=0.26, \mathrm{P}=0.61$ ) and stand age $(\mathrm{F}$ value $=2.80, \mathrm{P}=0.11)$ did not significantly affect stability in planted forest (Fig. S3 a and $\mathrm{c}$ )

The conditional average models for natural forest productivity change included precipitation, stand age, latitude, soil depth, and tree density (Fig. 4b). Annual precipitation ( $\mathrm{Z}$ value $=3.73, \mathrm{P}=0.0002)$, soil depth ( $\mathrm{Z}$ value $=5.51, \mathrm{P}<0.0001)$, and latitude $(\mathrm{Z}$ value $=5.68, \mathrm{P}<0.0001)$ played a significant positive role in productivity in natural forest (Fig. 4b). Productivity decreased with Stand age was in natural forest $(\mathrm{Z}$ value $=5.87$, $\mathrm{P}<0.0001$ ) (Fig. 4b). No significant effect of tree density on productivity in natural forest was observed ( $\mathrm{Z}$ value $=0.16, \mathrm{P}=0.87$ ) (Fig. $4 \mathrm{~b}$ ). The change in productivity in planted forest was most strongly affected by stand age, tree density, richness, and altitude. Productivity increased significantly with richness ( $\mathrm{Z}$ value $=4.42, \mathrm{P}<0.0001)$ and tree density $(\mathrm{Z}$ value $=3.38 \mathrm{P}=0.00072)$ (Fig. $4 \mathrm{~b})$, and decreased significantly with stand age $(\mathrm{Z}$ value $=3.71, \mathrm{P}=0.00021)$ (Fig. 4b). Productivity of planted forests was higher at higher altitudes $(\mathrm{Z}$ value $=2.25, \mathrm{P}=0.025$ ) (Fig. $3 \mathrm{~b}$ ). Based on the GAMM models, the productivity of natural ( $\mathrm{F}$ value $=25.95, \mathrm{P}<0.0001)$ and planted forest $(\mathrm{F}$ value $=4.49, \mathrm{P}=0.011)$ increased logarithmically with tree density (Fig. S2 d) but displayed contrasting patterns with tree density. Productivity also increased nearlogarithmically with stand age $(\mathrm{F}$ value $=5.80, \mathrm{P}<0.0001)$ in natural forest $(\mathrm{Fig} . \mathrm{S} 3 \mathrm{f})$, and stand age had negative and linear effects on the present-day productivity of planted forest ( $\mathrm{F}$ value $=-1.96, \mathrm{P}=0.050$ ). Richness played a positive role in productivity in planted forest $(\mathrm{F}$ value $=17.72, \mathrm{P}<0.0001)$ but not in natural forest ( $\mathrm{F}$ value $=0.64, \mathrm{P}=0.43$ ) (Fig. $\mathrm{S} 3 \mathrm{e}$ ). In general, the results of the GAMM models and GLS models were consistent.

3.3 Coupling effects of environmental and forest structure attributes on the productivity and 


\section{stability of planted and natural forests}

To clarify the effects of environmental and forest structure factors on natural forest stability, we fitted a piecewise SEM. Our model elucidated $38 \%$ of the variation in AGB stability and confirmed that the most important determinant of stability was the direct positive influence of stand age and the direct negative effect of precipitation decline (Fig. 5a). Latitude played a direct significant influence on AGB stability and an indirect influence via precipitation. Deeper soil depth facilitates increases in tree density in natural forest. The SEM model demonstrated that all predictor together clarified $61 \%$ of the variation in the AGB stability of planted forest (Fig. 5b). Stand age significantly and actively worked on the stability of planted forest. Richness made a negative impact on the stability of planted forest. Canopy had a direct positive impact on richness. Canopy and stand age had a direct positive effect on tree density. More detailed information in the SEM was presented in Table S2.

In natural forest, the predictors expounded $38 \%$ of the productivity change. Soil depth and precipitation had direct positive effects on productivity. Productivity decreased significantly with stand age. Latitude affected productivity directly as well as indirectly via precipitation (Fig. 5c). All predictors together expounded $75 \%$ of the productivity change in planted forest. Altitude, richness, and tree density had positive, direct effects on productivity. Stand age made a direct negative impact on productivity and an indirect impact via tree density (Fig. 5d). Canopy played an indirect positive role in productivity via density and richness.

\section{Discussion}

\subsection{Dynamics change in productivity and AGB stability from 1979 to 2017}

Within the past several decades, land that is not conducive to farming has been converted from arable to woodland to recovery wood products and carbon store, including natural forest and plantation. Our results showed that unharvested planted forest had higher productivity than natural forest, which suggests that planted forests have high C uptake and C sequestration (Tong et al., 2020). However, natural forest stored large amounts of carbon and showed an apparent decline in productivity, natural forests in our study with mean stand age 80 years old, whose biomass may achieve a state of dynamic stability. Chazdon et al. (2016) also indicated that the mature natural forest' $\mathrm{s}$ biomass has reached a climax state and their productivity declined. In addition, the AGB temporal stability in planted and natural forests decreased. As we know, AGB temporal stability in natural forest was more stability. In the following, we discussed possible causes underlying the observed trends and differences in AGB stability and productivity changes between the two forest types, and put forward corresponding management measures.

\subsection{Impact of forest structure on forest productivity and AGB stability}

The major difference in productivity and AGB stability between natural and planted forests came to the prominence of stand age, richness, and density (Fig. 4). As the delta AGB in forest decreases with stand age and time (Chen and Luo, 2015), we found that productivity markedly came down with stand age in planted forest (Fig. S3f), which may stem from tree growth decline (Gower et al., 1996). However, both productivity and AGB stability in natural forests finally achieved a stable state with stand age (Fig. S3 c and f). The longevity of dominant species complicate forest age, especially in planted forests where tree species with shorter lifespans mature more quickly than long-lived ones. Thus, Natural forests have a variety of dominant tree species, some age-controlled appearance may be masked by the complex forest structure. In addition, stand age may affect productivity and stability via changes of density and species richness as forests development (Ouyang et al., 2019).

Our results partly verified that richness increased productivity in planted forest but not in natural forest. The niche complementarity effect (Aussenac et al., 2019) and selection probability effect (Isbell et al., 2018) potentially explain the positive impact of richness on productivity in planted forest. In addition, richness also caused the increase of mean $(\mu)$ and standard deviation (SD) of AGB in planted forest; annual variation in the standard deviation (SD) of AGB might be similar to the change amplitude in mean value $(\mu)$. This may stem from the high synchrony in the selected tree species in the planted forest, which weakens the effect of 
richness on stability (Valencia et al., 2020). Nevertheless, temporal stability in biomass was not affected by plant species diversity in natural forest but may be decided by dominant species and asynchronous population dynamics (Ma et al., 2017), especially in late-successional stages (Guo and Ren, 2014). The mean stand age of natural forest was about 80 years, which is significantly higher than the mean stand age of plantations (17 years) in our study. The natural forest may be more mature.

\subsection{Environmental effects on forest productivity and stability}

Unlike natural forests, plantation location is determined by humans. The location of these two forest types had a significant difference (Fig. 1). The plantation in this study was located in the southern portion of the rainy zone in West China (Sichuan Vegetation Cooperation Group, 1980); the annual precipitation $(911.69 \pm 118.66 \mathrm{~mm})$ is greater in this area than in the area of natural forest $(787.08 \pm 137.08 \mathrm{~mm})$. This may make natural forests in less precipitation environment more sensitive to annual precipitation changes. Higher forest productivity at sites with suitable conditions suggested that a favorable resource (e.g., soil depth and annual precipitation) increased productivity (Forrester and Bauhus, 2016). MAT did not significantly affect productivity. While, links between rainfall and total productivity are highly temperature-dependent, where at least at tropical mountain rainforest sites experiencing low temperatures (16), increasing rainfall exerted a negative effect on productivity (Taylor et al. 2017). This may stem from the climatic context in our study region, which is characterized by a low MAT $(0 \sim 17)$. In addition, the response of forests to climate change strongly depends on forest composition and structure, and most of the natural forests in this study were composed of multiple late-successional Fir, Spruce and Betula in this study. It is consistent with Chen and Luo (2015), which showed that coniferous forest was more sensitive to climate change. The trees species and community compose in natural forest may explain differences between the two forest types.

\section{Suggestions for forest sustainable management}

Under the pressure of climate change, China government commit to reduce carbon emission, achieve carbon peak by 2030 and carbon neutrality by 2060. Although the forest carbon stocks increased in China in past several decades, our results showed that AGB stability in planted and natural forests decreased significantly over time, productivity also decreased over time in natural forest but not in planted forest. In combination with the increasing scarcity of land available for new forest plantations (Lambin and Meyfroidt, 2011), our results draw a much more complex and worrying picture.

The existing plantation forests are commonly stocked with fast-growing tree species that dominate early pioneer stages in natural forests. In turn, these trees are generally more short-lived than species typically dominating later successional phases (Norden et al., 2012), while the low diversity, often not only in view of species richness, but also genetic diversity (Liu et al., 2018) of plantation forests also makes them less resilient to pest outbreaks (Jactel and Brockerhoff, 2007) and other environmental stressors (Drever et al., 2006). One way to sustain the $\mathrm{C}$ sequestration specifically of the plantation forests into the future could therefore be enrichment planting of plantation forest plots with a diverse set of local, shade tolerant late-successional species under the existing plantation forest canopy. These trees could then take over once the initially planted fast-growing pioneer species start to die off. Human interventions, especially the targeted extraction of individual stems of fast-growing, not locally native trees like Eucalyptus spp. or Poplarspp., could further accelerate this transformative process, while also creating a more heterogeneous forest environment that potentially allows a greater mix of trees differing in shade tolerance to colonize or be planted under the existing trees. If extracted timber was used for example in buildings or other ways that store the carbon contained in the timber over long periods of time, this approach could actually further optimize the carbon sequestration of these forests over long time-spans, eventually creating a forest structure that is species-rich and heterogeneous also in its age and size class distribution that could be sustained almost indefinitely under a targeted, selection cutting regime, hence providing sustainable $\mathrm{C}$ sequestration benefits while increasingly mimicking the structure and diversity of the natural forest environment.

In contrast, we strongly suggest to strictly protect all - mature and secondary - natural forests from any human interventions - apart from a potential enrichment planting with tree species well adapted to the 
predicted, dryer and warmer future climatic conditions. The target here should be to allow the eventual natural domination of well-adapted long-lived late-succession tree species that commonly store significant amounts of carbon in their trunks (Smith and Knapp, 2003), with natural disturbances allowing for an overall heterogeneous forest environment that not only sustainably stores carbon, but also supports the extremely high levels of biodiversity encountered across our study region (Sun et al., 2021).

\section{Acknowledgments}

Funding: This work was funded by the Public Fund of Key Laboratory of Southwest Wildlife Resources Conservation, Ministry of Education, China (XNYB21-06), the Second Tibetan Plateau Scientific Exploration (2019QZKK0404), the Global Target Grid System Construction and Grid Location Service (grant number 2018YFB0505303).

\section{Credit authorship contribution statement}

Ting Li and Qi Wang analyzed data and wrote the manuscript. Ting Li, Yang Liu and Changhong Lai collected the data. All authors dedicated to the final preparation of the manuscript.

\section{Conflict of interest statement}

We guarantee that there is no conflict of interest in this manuscript.

\section{References}

Aussenac, R., Bergeron, Y., Gravel, D., Drobyshev, I. (2019). Interactions among trees: A key element in the stabilising effect of species diversity on forest growth. Functional Ecology 33, 360-367. DOI: 10.1111/13652435.13257

Babst, F., Bouriaud, O., Poulter, B., Trouet, V., Girardin, M.P., Frank, D.C. (2019). Twentieth century redistribution in climatic drivers of global tree growth. Science advances 5, eaat4313. DOI: 10.1126/sciadv.aat 4313

Bauhus, J., Forrester, D.I., Pretzsch, H. (2017). From Observations to Evidence About Effects of MixedSpecies Stands. In: Pretzsch, H., Forrester, D.I., Bauhus, J. (Eds.), Mixed-Species Forests: Ecology and Management. Springer Berlin Heidelberg, Berlin, Heidelberg, pp. 27-71. DOI: 10.1007/978-3-662-54553-9_2

Barton, K. Package 'MuMIn'. Version, 1, 2015, 18.

Brown, H.C.A., Berninger, F.A., Larjavaara, M., Appiah, M. (2020). Above-ground carbon stocks and timber value of old timber plantations, secondary and primary forests in southern Ghana. Forest Ecology and Management 472, 118236. DOI: 10.1016/j.foreco.2020.118236

Chazdon, R.L., Broadbent, E.N., Rozendaal, D.M., Bongers, F., Zambrano, A.M., Aide, T.M., ... Poorter, L. (2016). Carbon sequestration potential of second-growth forest regeneration in the Latin American tropics. Science advances 2, e1501639. DOI: 10.1126/sciadv.1501639

Chen, H.Y.H., Luo, Y. (2015). Net aboveground biomass declines of four major forest types with forest ageing and climate change in western Canada's boreal forests. Global Change Biology 21, 3675-3684. DOI: $10.1111 /$ gcb.12994

Cook-Patton, S.C., Leavitt, S.M., Gibbs, D., Harris, N.L., Lister, K., Anderson-Teixeira, K.J., ... Griscom, B.W. (2020). Mapping carbon accumulation potential from global natural forest regrowth. Nature 585, 545-550. DOI: 10.1038/s41586-020-2686-x

Cui, H., Liu, M. (2020). Analysis on the Results of The 9th National Forest Inventory. Journal of West China Forestry Science, 49, 90-95. (In Chinese)

Deng, L., Liu, S., Kim, D.G., Peng, C., Sweeney, S., Shangguan, Z. (2017). Past and future carbon sequestration benefits of China's grain for green program. Global Environmental Change 47, 13-20. DOI: 10.1016/j.gloenvcha.2017.09.006 
Dominguez-Garcia, V., Dakos, V., Kefi, S. (2019). Unveiling dimensions of stability in complex ecological networks. Proceedings of the National Academy of Sciences 116, 25714. DOI: 10.1073/pnas.1904470116

Drever, C. R., Peterson, G., Messier, C., Bergeron, Y., Flannigan, M. (2006). Can forest management based on natural disturbances maintain ecological resilience? Canadian journal of forest research,36(9), 2285-2299. DOI: $10.1139 / \mathrm{x} 06-132$

Fang, J., Chen, A., Peng, C., Zhao, S., Ci, L. (2001). Changes in Forest Biomass Carbon Storage in China Between 1949 and 1998. Science 292, 2320. DOI: 10.1126/science.1058629

Forrester, D.I., Bauhus, J. (2016). A Review of Processes Behind Diversity_Productivity Relationships in Forests. Current Forestry Reports 2, 45-61. DOI: 10.1007/s40725-016-0031-2

Garcia-Palacios, P., Gross, N., Gaitan, J., Maestre, F.T. (2018). Climate mediates the biodiversityecosystem stability relationship globally. Proceedings of the National Academy of Sciences 115, 8400. DOI: $10.1073 /$ pnas. 1800425115

Gower, S.T., McMurtrie, R.E., Murty, D. (1996). Aboveground net primary production decline with stand age: potential causes. Trends in Ecology \& Evolution 11, 378-382. DOI: 10.1016/0169-5347(96)10042-2

Grueber, C.E., Nakagawa, S., Laws, R.J., Jamieson, I.G. (2011). Multimodel inference in ecology and evolution: challenges and solutions. Journal of Evolutionary Biology 24, 699-711. DOI: 10.1111/j.14209101.2010.02210.x

Guo, Q., Ren, H. (2014). Productivity as related to diversity and age in planted versus natural forests. Global Ecology and Biogeography 23, 1461-1471. DOI: 10.1111/geb.12238

Guo, Z., Wang, X., Fan, D. (2021). Ecosystem functioning and stability are mainly driven by stand structural attributes and biodiversity, respectively, in a tropical forest in Southwestern China. Forest Ecology and Management 481, 118696. DOI: 10.1016/j.foreco.2020.118696

Hautier, Y., Tilman, D., Isbell, F., Seabloom, E.W., Borer, E.T., Reich, P.B. (2015). Anthropogenic environmental changes affect ecosystem stability via biodiversity. Science 348, 336. DOI: 10.1126/science.aaa1788

Hisano, M., Chen, H.Y.H., Searle, E.B., Reich, P.B. (2019). Species-rich boreal forests grew more and suffered less mortality than species-poor forests under the environmental change of the past half-century. Ecology letters 22, 999-1008. DOI: 10.1111/ele.13259

Isbell, F., Gonzalez, A., Loreau, M., Cowles, J., Diaz, S., Hector, A., ... Larigauderie, A. (2017). Linking the influence and dependence of people on biodiversity across scales. Nature 546, 65-72. DOI: 10.1038/nature22899

Isbell, F., Cowles, J., Dee, L.E., Loreau, M., Reich, P.B., Gonzalez, A., Hector, A., Schmid, B. (2018). Quantifying effects of biodiversity on ecosystem functioning across times and places. Ecology Letters 21, 763-778. DOI: $10.1111 /$ ele.12928

Isbell, F., Tilman, D., Reich, P.B., Clark, A.T. (2019). Deficits of biodiversity and productivity linger a century after agricultural abandonment. Nature Ecology \& Evolution 3, 1533-1538. DOI: 10.1038/s41559019-1012-1

Jactel, H., Brockerhoff, E. G. (2007). Tree diversity reduces herbivory by forest insects. Ecol Lett, 10(9), 835-848. DOI: $10.1111 / \mathrm{j} .1461-0248.2007 .01073 . x$

Jucker, T., Bouriaud, O., Avacaritei, D., Coomes, D.A. (2014). Stabilizing effects of diversity on aboveground wood production in forest ecosystems: linking patterns and processes. Ecology letters 17, 1560-1569. DOI: 10.1111/ele. 12382

Ke, S., Qiao, D., Yuan, W., He, Y. (2020). Broadening the scope of forest transition inquiry: What does China's experience suggest? Forest Policy and Economics 118, 102240. DOI: 10.1016/j.forpol.2020.102240 
Lambin, E. F., Meyfroidt, P. (2011). Global land use change, economic globalization, and the looming land scarcity. Proceedings of the National Academy of Sciences, 108(9), 3465. DOI: 10.1073/pnas.1100480108

Lefcheck, J.S. (2016). piecewiseSEM: piecewise structural equation modelling in $\mathrm{r}$ for ecology, evolution, and systematics.Methods Ecol. Evol. 7, 573 - 579. DOI: 10.1111/2041-210X.12512

Liang, J., Crowther, T.W., Picard, N., Wiser, S., Zhou, M., Alberti, G., ...Reich, P.B. (2016). Positive biodiversity-productivity relationship predominant in global forests. Science 354. DOI: 10.1126/science.aaf8957

Liu, C. L. C., Kuchma, O., Krutovsky, K. V. (2018). Mixed-species versus monocultures in plantation forestry: Development, benefits, ecosystem services and perspectives for the future. Global Ecology and Conservation, 15, e00419. DOI: 10.1016/j.gecco.2018.e00419

Luo, W., Liang, J., Cazzolla Gatti, R., Zhao, X., Zhang, C. (2019). Parameterization of biodiversityproductivity relationship and its scale dependency using georeferenced tree-level data. Journal of Ecology 107, 1106-1119. DOI: $10.1111 / 1365-2745.13129$

Ma, Z., Liu, H., Mi, Z., Zhang, Z., Wang, Y., Xu, W., Jiang, L., He, J.-S. (2017). Climate warming reduces the temporal stability of plant community biomass production. Nature Communications 8, 15378. DOI: $10.1038 /$ ncomms 15378

Morin, X., Fahse, L., de Mazancourt, C., Scherer-Lorenzen, M., Bugmann, H. (2014). Temporal stability in forest productivity increases with tree diversity due to asynchrony in species dynamics. Ecology Letters 17, 1526-1535. DOI: $10.1111 /$ ele.12357

Mori, A.S., Isbell, F., Seidl, R. (2018). $\beta$-Diversity, Community Assembly, and Ecosystem Functioning. Trends in Ecology \& Evolution 33, 549-564. DOI: 10.1016/j.tree.2018.04.012

Norden, N., Letcher, S. G., Boukili, V., Swenson, N. G., Chazdon, R. (2012). Demographic drivers of successional changes in phylogenetic structure across life-history stages in plant communities.Ecology, 93 (sp8), S70-S82. DOI: 10.1890/10-2179.1

Ouyang, S., Xiang, W., Wang, X., Xiao, W., Chen, L., Li, S., .. Peng, C. (2019). Effects of stand age, richness and density on productivity in subtropical forests in China. Journal of Ecology 107, 2266-2277. DOI: $10.1111 / 1365-2745.13194$

Pawson, S.M., Brin, A., Brockerhoff, E.G., Lamb, D., Payn, T.W., Paquette, A., Parrotta, J.A. (2013). Plantation forests, climate change and biodiversity. Biodiversity and Conservation 22, 1203-1227. DOI: 10.1007/s10531-013-0458-8

Piao, S.L., Cui, M.D., Chen, A.P. (2011). Altitude and temperature dependence of change in the spring vegetation green-up date from 1982 to 2006 in the Qinghai-Xizang Plateau. Agricultural and Forest Meteorology 151, 1599-1608. DOI: 10.1016/j.agrformet.2011.06.016

Pinheiro, J. (2020). nlme:Linear and Nonlinear Mixed Effects Models. R package version 3.1-150.

R Core Team. (2018). R: A language and environment for statistical computing, R Foundation for Statistical Computing, Vienna, Austria.

Ratcliffe, S., Wirth, C., Jucker, T., van der Plas, F., Scherer-Lorenzen, M., Verheyen, K., ... Baeten, L. (2017). Biodiversity and ecosystem functioning relations in European forests depend on environmental context. Ecology letters 20, 1414-1426. DOI: 10.1111/ele.12849

Ren, Y., Lü, Y., Fu, B., Zhang, K. (2017). Biodiversity and Ecosystem Functional Enhancement by Forest Restoration: A Meta-analysis in China. Land Degradation \& Development 28, 2062-2073. DOI: 10.1002/ldr.2728

Rousset, F., Ferdy, J., Courtiol, A. (2018). spaMM: Mixed models, particularly spatial models. R package version, 2.4.35. 
Satdichanh, M., Ma, H., Yan, K., Dossa, G.G.O., Winowiecki, L., Vågen, T.-G., ... Harrison, R.D. (2019). Phylogenetic diversity correlated with above-ground biomass production during forest succession: Evidence from tropical forests in Southeast Asia. Journal of Ecology 107, 1419-1432. DOI: 10.1111/1365-2745.13112

Smith, M. D., Knapp, A. K. (2003). Dominant species maintain ecosystem function with non-random species loss. Ecology Letters, 6(6), 509-517. DOI: 10.1046/j.1461-0248.2003.00454.x

Sichuan Vegetation Cooperation Group. Sichuan vegetation. (1980). pp.190, Sichuan people's publishing house, Chengdu, China.

Sun, Y., Liu, S., Liu, Y., Dong, Y., Li, M., An, Y., Beazley, R. (2021). Effects of the interaction among climate, terrain and human activities on biodiversity on the Qinghai-Tibet Plateau. Science of The Total Environment, 794, 148497. DOI: 10.1016/j.scitotenv.2021.148497

Taylor, P.G., Cleveland, C.C., Wieder, W.R., Sullivan, B.W., Doughty, C.E., Dobrowski, S.Z., Townsend, A.R. (2017). Temperature and rainfall interact to control carbon cycling in tropical forests. Ecology letters 20, 779-788. DOI: $10.1111 /$ ele.12765

Tong, X., Brandt, M., Yue, Y., Ciais, P., Rudbeck Jepsen, M., Penuelas, J., .. Fensholt, R. (2020). Forest management in southern China generates short term extensive carbon sequestration. Nature Communications 11, 129. DOI: 10.1038/s41467-019-13798-8

Trotsiuk, V., Hartig, F., Cailleret, M., Babst, F., Forrester, D.I., Baltensweiler, A., ... Schaub, M. (2019). Assessing the response of forest productivity to climate extremes in Switzerland using model-data fusion. Global Change Biology 26, 2463-2476. DOI: 10.1111/gcb.15011

Valencia, E., de Bello, F., Galland, T., Adler, P.B., Lepš, J., E-Vojtkó, A., .. Götzenberger, L. (2020). Synchrony matters more than species richness in plant community stability at a global scale. Proceedings of the National Academy of Sciences 117, 24345. DOI: 10.1073/pnas.1920405117

Verheyen, K., Vanhellemont, M., Auge, H., Baeten, L., Baraloto, C., Barsoum, N., ... Scherer-Lorenzen, M. (2016). Contributions of a global network of tree diversity experiments to sustainable forest plantations. Ambio 45, 29-41. DOI: 10.1007/s13280-015-0685-1

Wang, X. M., Lu, Y. C., Xing, H. T., Zeng, J., Xie, Y. S., Cai, D. X., Liu, X. Z., Zhang, X. Q. (2018). Effects of Close-to-Nature Conversion on Pinus massoniana Plantations at Different Stand Developmental Stages, Tropical Conservation Science 11, 1-16. DOI: 10.1177/1940082918767953

Wood, S.N. (2017). Generalized Additive Models: An introduction with R. Chapman and Hall / CRC, Boca Raton, FL.

Yao, Y., Wang, X., Li, Y., Wang, T., Shen, M., Du, M., ... Piao, S. (2018). Spatiotemporal pattern of gross primary productivity and its covariation with climate in China over the last thirty years. Global Change Biology 24, 184-196. DOI: 10.1111/gcb.13830

Zhang, J., Fu, B., Stafford-Smith, M., Wang, S., Zhao, W. (2020). Improve forest restoration initiatives to meet Sustainable Development Goal 15. Nature Ecology \& Evolution 5, 10-13. DOI: 10.1038/s41559-020$01332-9$

Zuur, A., Ieno, E.N., Walker, N., Saveliev, A.A., Smith, G. M. (2009). Mixed effects models and extensions in ecology with R., Stanford: Springer Science \& Business Media. 


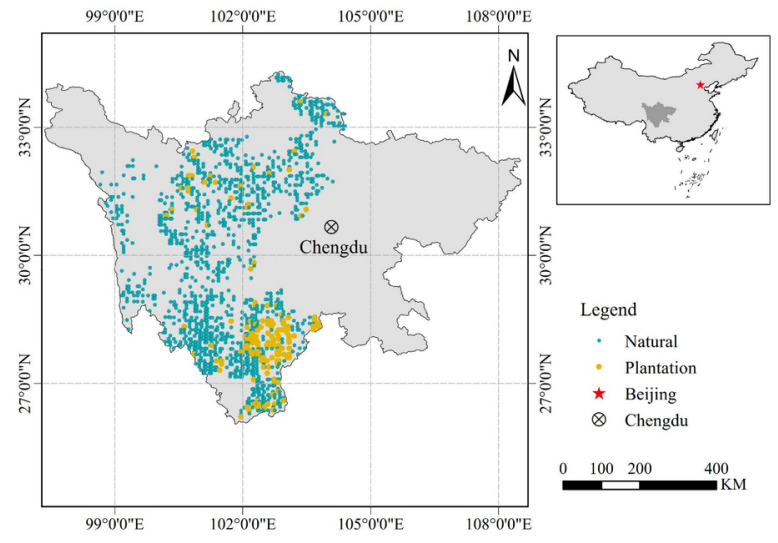

Figure 1 Distribution of the permanent sampling plots ([?]2 censuses) in Sichuan Province, China
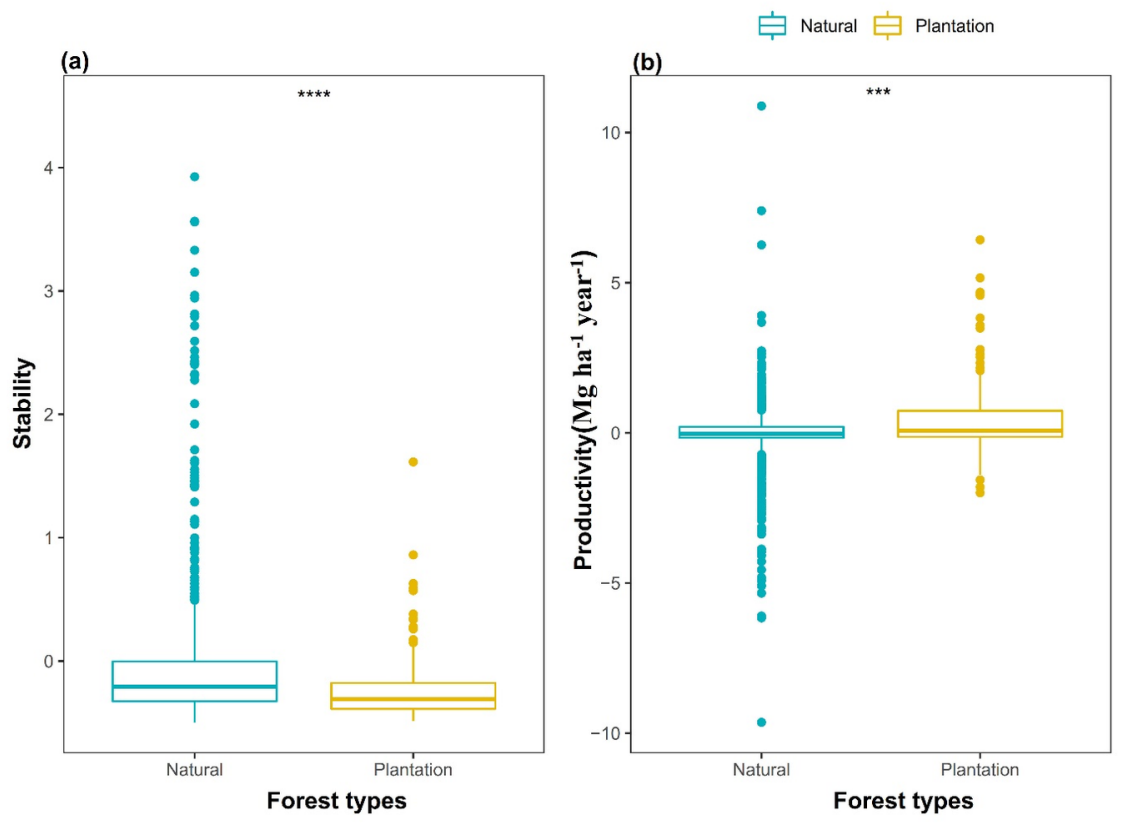

Figure 2 Comparison of the temporal mean value of relative above-ground biomass stability and productivity(scale) in planted and natural forests over the past four decades. Significant differences between planted and natural forests are indicated by stars: ${ }^{*} \mathrm{p}<0.05,{ }^{* *} \mathrm{p}<0.01,{ }^{* * *} \mathrm{p}<0.001,{ }^{* * * *} \mathrm{p}<0.0001$. 

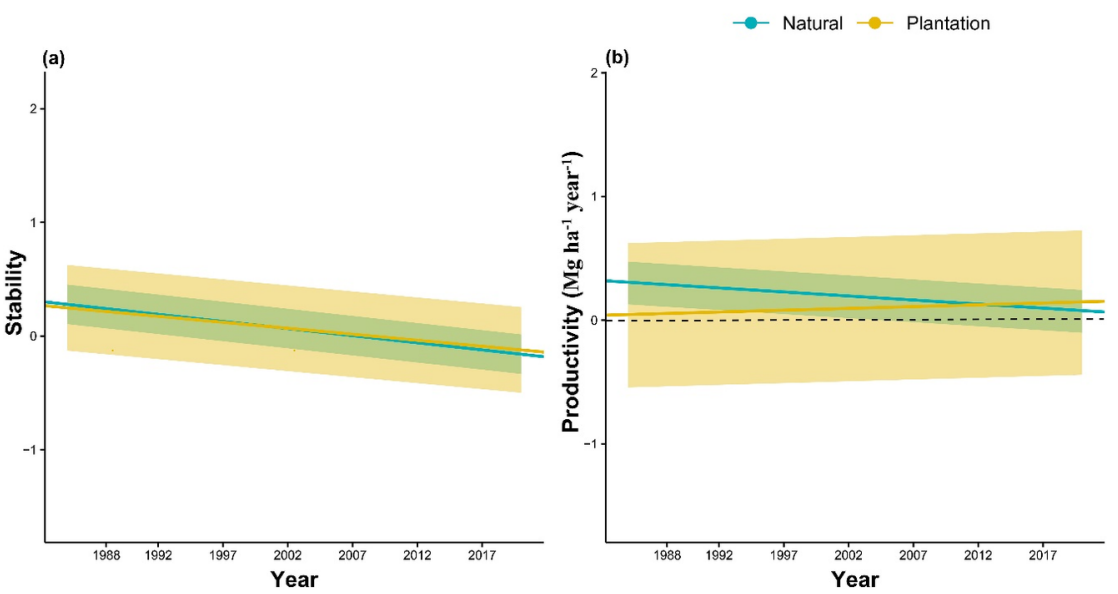

Figure 3 Temporal changes in relative AGB stability (a) and productivity (b) (scale) in planted and natural forests. The lines and shaded areas show the estimates and $95 \%$ confidence intervals of the coefficients of the LME, respectively.
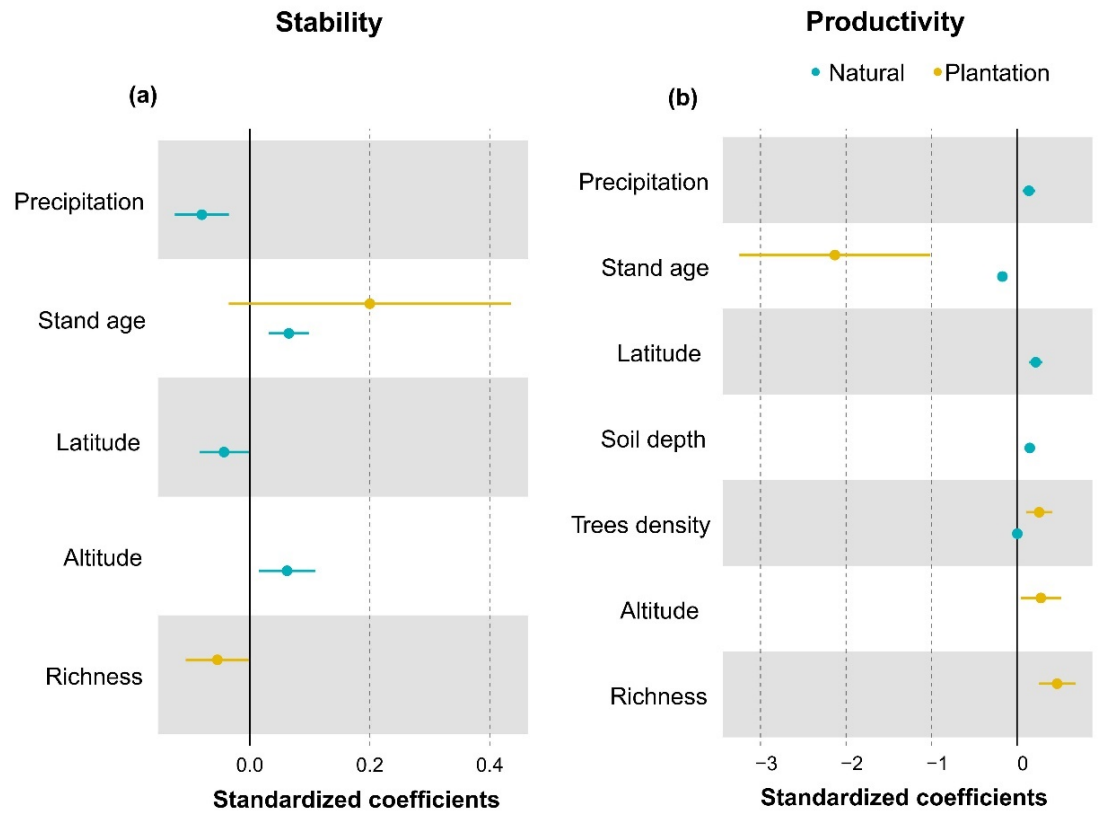

Figure 4 Standardized effect sizes in the conditional average models (GLS, delta AIC $<4$ ) for AGB stability and productivity in plantation and natural forests after accounting for spatial autocorrelation. Dots are on behalf of the standardized effect size of existing variable, and lines are on behalf of 1 S.D. 

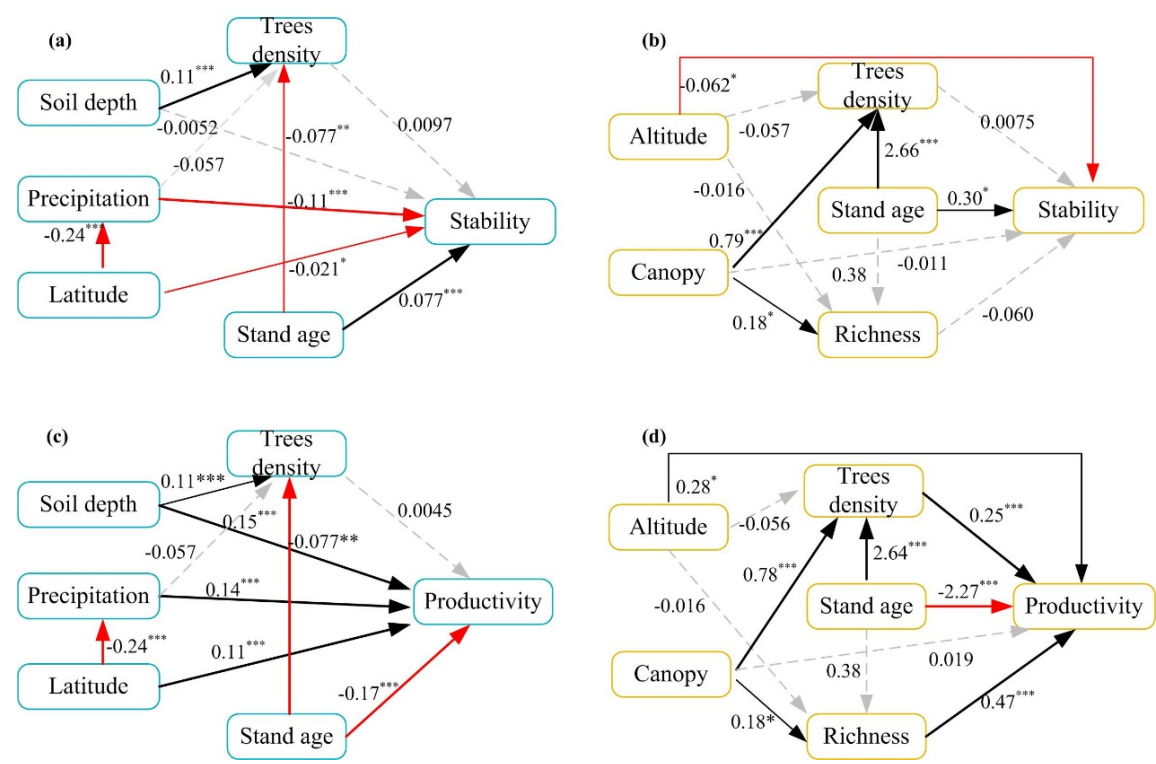

Figure 5 Piecewise SEM displayed the coupling influence of multiple environmental and forest structure factors on AGB stability and productivity of natural forest and planted forest (natural forest stability (Fig. 5a): Fisher's $\mathrm{C}$ statistic: $\mathrm{C}=8.23, \mathrm{P}=0.22, \mathrm{df}=1209$; planted forest stability (Fig. 5b): Fisher's $\mathrm{C}$ statistic: $\mathrm{C}=0.18, \mathrm{P}=0.92, \mathrm{df}=139$; natural forest productivity: Fisher's $\mathrm{C}$ statistic (Fig. $5 \mathrm{c}$ ): $\mathrm{C}=8.23, \mathrm{P}=0.22$, $\mathrm{df}=1209$; planted forest productivity (Fig. $5 \mathrm{~d}$ ): Fisher's $\mathrm{C}$ statistic: $\mathrm{C}=0.18, \mathrm{P}=0.92, \mathrm{df}=139$ ). Dark lines show positive effects, and red lines show negative effects. Solid lines indicated noticeable effects, and gray lines indicate insignificant effects (Table S2). 